\title{
Structural Stabilizing Effect of Zn Substitution on MnAl and Its Magnetic Properties
}

\author{
H. X. Wang ${ }^{1}$, P. Z. Si ${ }^{1, *}$, W. Jiang ${ }^{1}$, J. G. Lee ${ }^{2}$, C. J. Choi ${ }^{2}$, J. J. Liu ${ }^{3}$, \\ Q. Wu ${ }^{1}$, M. Zhong ${ }^{1}$, H. L. Ge ${ }^{1}$ \\ ${ }^{1}$ School of Materials Science and Engineering, China Jiliang University, \\ Hangzhou, China \\ ${ }^{2}$ Korea Institute of Materials Science, Changwon, Gyeongnam, R. Korea \\ ${ }^{3}$ Faculty of Materials Science and Chemical Engineering, \\ Ningbo University, Ningbo, China \\ E-mail:pzsi@mail.com \\ Received May 17, 2011; revised June 28, 2011; accepted July 12, 2011
}

\begin{abstract}
The effect of $\mathrm{Zn}$ substitution on the structure and magnetic properties of $\tau$-MnAl has been investigated systematically. It is found that $\mathrm{Zn}$ substitution can stabilize the structure of $\tau$-phase and thus a significant amount of $\tau$-phase can be produced. $\mathrm{Zn}$ increases the coercivity and saturation magnetization of the $\tau$-MnAl but reduces the Currie temperature. However, excess $\mathrm{Zn}$ is detrimental to the magnetic parameters. The optimum magnetic performance was found in samples with $\mathrm{Zn}$ substitution to $2.9 \% \mathrm{Mn}$ atoms and $3.5 \% \mathrm{Al}$ atoms, respectively.
\end{abstract}

Keywords: MnAl, Magnetic Property, Zn Substitution

\section{Introduction}

The development of rare earth free permanent magnets is becoming more and more important with increasing cost and decreasing reserve of rare earth resources. Ferromagnetic $\tau-\mathrm{MnAl}$, as a low cost rare-earth-free magnet, has received continuous attention since its discovery in 1958 for its superior magnetic performance in comparison with magnetically hard ferrites and Alnicos [1-3]. The $\tau$-MnAl has a Currie temperature of $661 \mathrm{~K}$, a manganese moment of $1.94 \mu_{B}$, and an enhanced magnetic anisotropy. The structure of ferromagnetic $\tau$-MnAl is tetragonal, which can be interpreted to arise from a nonmagnetic cubic structure by two subsequent steps, namely an electronic distortion due to spin polarization followed by a structural distortion into the tetragonal system [4]. Since the $\tau$-MnAl is metastable, it is difficult to obtain pure phase of $\tau$-MnAl, which usually is produced by a rapid quench of the high temperature $\varepsilon$-phase followed by isothermal annealing at temperatures between $400^{\circ} \mathrm{C}$ and $700^{\circ} \mathrm{C}$ for a short while, or by cooling the $\tau$-phase at a rate of $10^{\circ} \mathrm{C} / \mathrm{min}$ [2]. Long time annealing would result in decomposition of the $\tau$-phase to the equilibrium $\gamma$-phase and $\beta$-phase. In order to stabilize the
$\tau-\mathrm{MnAl}$, the doping effect of several elements, including $\mathrm{Ti}, \mathrm{Cu}, \mathrm{Ni}, \mathrm{C}, \mathrm{B}$, etc., has also been studied [2,5]. It was found that the addition of carbon to $\mathrm{MnAl}$ can stabilize the $\tau$-phase [6,7]. Reports on the partial substitution of $\mathrm{Mn}$ in $\mathrm{MnAl}$ by Ni or Co could also be found [8,9]. The effect of introducing other elements into MnAl system has not been studied. The purpose of this work is to investigate the effect of doping $\mathrm{Zn}$ on the structure and magnetic properties of the Mn-Al system.

\section{Experiments}

High purity $(>99.9 \%) \mathrm{Mn}, \mathrm{Al}$ and $\mathrm{Zn}$ in nominal composition of $\mathrm{Mn}_{54} \mathrm{Al}_{46-\delta} \mathrm{Zn}_{\delta}(\delta=0,1.6,3.3,4.7,5), \mathrm{Mn}_{53.5}$ $\mathrm{Zn}_{0.5} \mathrm{Al}_{46}, \mathrm{Mn}_{53.4} \mathrm{Zn}_{1.6} \mathrm{Al}_{46}, \mathrm{Mn}_{51.8} \mathrm{Zn}_{3.2} \mathrm{Al}_{46}$, and $\mathrm{Mn}_{49} \mathrm{Zn}_{5}$ $\mathrm{Al}_{46}$ were melted by using induction meting in an argon atmosphere. Then the melt was quenched in water. After that the quenched ingots were annealed at $420^{\circ} \mathrm{C}$ for $1 \mathrm{~h}$ in vacuum, respectively. The structure of the samples was determined by using a powder x-ray diffractometer (XRD) with $\mathrm{Cu} K_{\alpha}$ radiation while the magnetic properties were measured by using a Vibrating Sample Magnetometer (VSM) in fields up to $1.5 \mathrm{~T}$. Thermal analysis on the samples was carried out in argon atmosphere with a 
temperature sweep rate of $20^{\circ} \mathrm{C} / \mathrm{min}$.

\section{Results and Discussion}

The X-ray powder diffraction patterns of the $\mathrm{Mn}_{54} \mathrm{Al}_{46-\delta}$ $\mathrm{Zn}_{\delta}(\delta=0,1.6,3.3,5)$ water quenched samples and their counterparts after $420^{\circ} \mathrm{C}$ and one hour vacuum heattreatment are shown in Figure 1, respectively. The XRD patterns for the as-quenched $\mathrm{Mn}_{54} \mathrm{Al}_{46}$, as shown in Figure 1(a), could be mainly indexed with orthorhombic $\varepsilon-\mathrm{MnAl}$ phase, which is stable at temperatures above $870^{\circ} \mathrm{C}$ and is maintained to room temperature during quench. The weak broadened peak in the vicinity of $43^{\circ}$ indicates the presence of $\gamma$ and/or $\beta$-phase as minor phase in the sample. Figure 1(b) shows that the heat-treatment to $\mathrm{Mn}_{54} \mathrm{Al}_{46}$ induces the transformation of $\varepsilon$-phase to a more stable Al-rich $\gamma$-phase and Mn-rich $\beta$-phase. The diffraction peaks for meta-stable $\tau$-phase could also be found but are very weak. Strong diffraction peaks appear in both water-quenched and heat-treated $\mathrm{Mn}_{54} \mathrm{Al}_{44.4} \mathrm{Zn}_{1.6}$, as shown in Figures 1(c) and (d), indicating stabilizing effect of $\mathrm{Zn}$ on the structure of $\tau$-phase. Trace amount of $\varepsilon$-phase, $\beta$-phase and $\gamma$-phase are detected in the asquenched $\mathrm{Mn}_{54} \mathrm{Al}_{44.4} \mathrm{Zn}_{1.6}$. After heat-treatment, the $\varepsilon$ phase disappears while the diffraction intensity of $\beta$ - and $\gamma$-phase made almost no change, indicating a phase transformation of $\varepsilon$-phase to $\tau$-phase during heat-treatment. For $\mathrm{Mn}_{54} \mathrm{Al}_{42.7} \mathrm{Zn}_{3.3}$, the $\tau$-phase presents in the as-quenched samples but disappears after heat-treatment, as seen in Figures 1 (e) and (f). These phenomena indicate that the $\tau$-phase formed in $\mathrm{Mn}_{54} \mathrm{Al}_{44.4} \mathrm{Zn}_{1.6}$ is more stable than that formed in $\mathrm{Mn}_{54} \mathrm{Al}_{42.7} \mathrm{Zn}_{3.3}$. With increasing $\mathrm{Zn}$ content, the $\tau$-phase, $\beta$-phase and $\gamma$-phase coexists in both water-quenched and heat-treated $\mathrm{Mn}_{54} \mathrm{Al}_{41} \mathrm{Zn}_{5}$ samples as seen in Figures 1(g) and (h).

It should be noted that for sample with $\delta=1.6, \tau$-phase is the major phase while for other samples $\beta$-phase is the major one. This result indicates that substitution of a certain amount of $\mathrm{Zn}$ to $\mathrm{Al}$ is beneficial for the formation of $\tau$-phase. We speculate that atomic size may play an important rule in this process. It is known that the atomic size of $\mathrm{Zn}$ is slightly smaller than that of Al. Since the minimum internal energy in MnAl occurs very close to $c / a=1$ ( $c$ and $a$ are the lattice parameters), thus the tetragonal $\tau$-phase is reported to be meta-stable [4]. When a small number of Al atoms were substituted by smaller Zn, a local lattice distortion that make tetragonal $\tau$-phase more stable might occur to maintain internal energy minimum. However, for samples with increasing substitution $\delta \geq 3.3, \beta$-phase rather than $\varepsilon$ or $\tau$-phase formed as major phase in water quenched samples. Since $\beta$-phase is very stable and thus the heat-treatment has little effect on the structure of these samples.
Figure 2 shows the effect of $\mathrm{Zn}$ substitution to $\mathrm{Al}$ on the magnetic properties of $\mathrm{Mn}_{54} \mathrm{Al}_{46-\delta} \mathrm{Zn}_{\delta}(\delta=0,1.6,3.3$, $5)$. For heat-treated samples, the coercivity and the saturation magnetization increase first and then decrease with increasing $\mathrm{Zn}$ substitution to Al. A maximum coercivity of $0.157 \mathrm{~T}$ was observed in heat-treated $\mathrm{Mn}_{54} \mathrm{Al}_{44.4} \mathrm{Zn}_{1.6}$. The $0.157 \mathrm{~T}$ coercivity in our Mn-Al-Zn system is lower than the $0.34 \mathrm{~T}$ coercivity as reported in the $\mathrm{Mn}-\mathrm{Al}-\mathrm{C}$ samples [7]. Since the parameter of coercivity is very sensitive to microstructures, we tend to believe that certain partial substitution of $\mathrm{Zn}$ to $\mathrm{Al}$ might result in the formation of localized lattice defects that hinder magnetization reversal. The increasing saturation magnetization with $\mathrm{Zn}$ substitution was ascribed to the structural stabilizing effect of $\mathrm{Zn}$ on ferromagnetic $\tau$-MnAl and its presence as major phase in the samples. Excess $\mathrm{Zn}$ would result in the formation of more $\beta$-phase and $\gamma$-phase that are detrimental to the magnetic performance. In comparison with heat-treated samples, most water-quenched samples exhibit a lower coercivity except $\mathrm{Mn}_{54} \mathrm{Al}_{42.7} \mathrm{Zn}_{3.3}$, as seen in Figure 2. However, for samples with $\delta \geq 3.3$, the effect of heat-treatment on the coer-

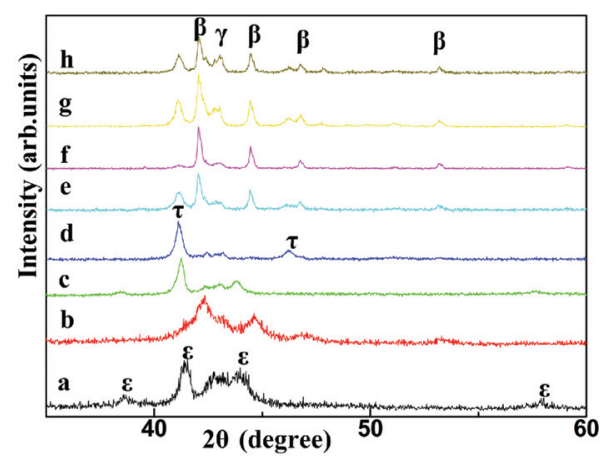

Figure 1. XRD patterns for (a) $\mathrm{Mn}_{54} \mathrm{Al}_{46}$, (b) Heat-treated $\mathrm{Mn}_{54} \mathrm{Al}_{46}$, (c) $\mathrm{Mn}_{54} \mathrm{Al}_{44.4} \mathrm{Zn}_{1.6}$, (d) Heat-treated $\mathrm{Mn}_{54} \mathrm{Al}_{44.4}$ $\mathrm{Zn}_{1.6}$, (e) $\mathrm{Mn}_{54} \mathrm{Al}_{42.7} \mathrm{Zn}_{3.3}$, (f) Heat-treated $\mathrm{Mn}_{54} \mathrm{Al}_{42.7} \mathrm{Zn}_{3.3}$, (g) $\mathrm{Mn}_{54} \mathrm{Al}_{41} \mathbf{Z n}_{5}$, and (h) Heat-treated $\mathrm{Mn}_{54} \mathrm{Al}_{41} \mathbf{Z n}_{5}$. The heattreatment for sample (b), (d), (f), and (h) was carried out in vacuum under $420^{\circ} \mathrm{C}$ for one hour.

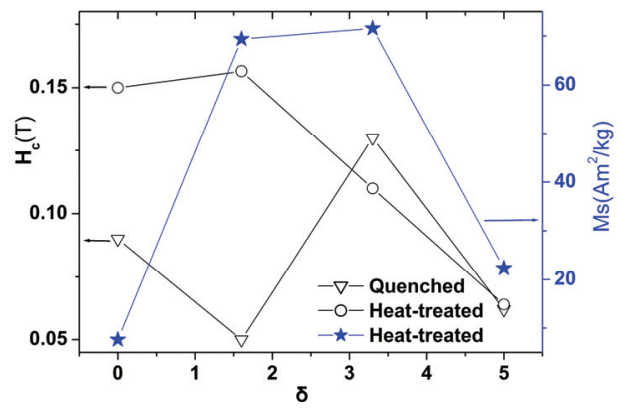

Figure 2. The effect of $\mathrm{Zn}$ substitution to $\mathrm{Al}$ on the coercivity and saturation magnetization of $\mathbf{M n}_{54} \mathbf{A l}_{46-\delta} \mathbf{Z n}_{\delta}(\delta=0$, 1.6, 3.3, 5). 
civity is decreasing due to the presence of stable $\beta$-phase and $\gamma$-phase in the samples. Heat-treatment has a strong effect on the magnetic properties of $\mathrm{Mn}_{54} \mathrm{Al}_{44.4} \mathrm{Zn}_{1.6}$.

Figure 3 shows the XRD patterns of the waterquenched and the heat-treated ingots of $\mathrm{Mn}_{53.5} \mathrm{Zn}_{0.5} \mathrm{Al}_{46}$, $\mathrm{Mn}_{53.4} \mathrm{Zn}_{1.6} \mathrm{Al}_{46}, \mathrm{Mn}_{51.8} \mathrm{Zn}_{3.2} \mathrm{Al}_{46}$, and $\mathrm{Mn}_{49} \mathrm{Zn}_{5} \mathrm{Al}_{46}$. It is interesting that $\tau$-phase formed in all water-quenched samples, indicating a strong structural stabilizing effect of $\mathrm{Zn}$ substitution to $\mathrm{Mn}$ on $\tau$-MnAl. However, the $\beta$-phase and $\gamma$-phase were also formed in all samples during water-quench. For $\mathrm{Mn}_{53.5} \mathrm{Zn}_{0.5} \mathrm{Al}_{46}$, as seen in Figures 3(a) and (b), by comparing the relative diffraction intensity of $\tau$-phase and $\beta$ - $/ \gamma$-phase, we noticed that the amount of $\tau$-phase increased after heat-treatment. Figures 3(c) and (d) shows that the heat-treatment has little effect on the structure of $\mathrm{Mn}_{53.4} \mathrm{Zn}_{1.6} \mathrm{Al}_{46}$. For $\mathrm{Mn}_{51.8} \mathrm{Zn}_{3.2} \mathrm{Al}_{46}$, $\varepsilon$-phase was detected in water-quenched sample while it disappears after heat-treatment, as shown in Figures 3(e) and (f). The intensity of $\tau$-phase peaks were enhanced after heat-treatment, indicating a $\varepsilon \rightarrow \tau$ transformation in this process. Figures 3(g) and (h) shows that both water-quenched and heat-treated $\mathrm{Mn}_{49} \mathrm{Zn}_{5} \mathrm{Al}_{46}$ were composed of $\tau$-phase, $\beta$-phase and $\gamma$-phase, while heat-treatment had almost no effect on the structure. Figure 3 shows that no pure $\tau$-phase could be obtained in $\mathrm{Zn}$ substituting Mn process, for comparison Figures 1(c) and (d) shows that pure $\tau$-phase could be obtained in $\mathrm{Zn}$ substituting Al process.

The effect of $\mathrm{Zn}$ substitution to $\mathrm{Mn}$ on the magnetic properties of $\mathrm{Mn}_{54} \mathrm{Al}_{46}, \mathrm{Mn}_{53.5} \mathrm{Zn}_{0.5} \mathrm{Al}_{46}, \mathrm{Mn}_{53.4} \mathrm{Zn}_{1.6} \mathrm{Al}_{46}$, $\mathrm{Mn}_{51.8} \mathrm{Zn}_{3.2} \mathrm{Al}_{46}$ and $\mathrm{Mn}_{49} \mathrm{Zn}_{5} \mathrm{Al}_{46}$ are shown in Figure 4. Both the saturation magnetization and the coercivity of the heat-treated samples increase first and then decrease with increasing $\mathrm{Zn}$ content. The maximum coercivity was observed in $\mathrm{Mn}_{53.5} \mathrm{Zn}_{0.5} \mathrm{Al}_{46}$ while the maximum saturation magnetization was observed in $\mathrm{Mn}_{53.4} \mathrm{Zn}_{1.6} \mathrm{Al}_{46}$. The enhancement of the magnetic performance for samples with lower $\mathrm{Zn}$ substitution indicates that $\mathrm{Zn}$ is beneficial for the formation of $\tau$-phase. However, Figure 4 also shows that higher $\mathrm{Zn}$ substitution is detrimental to the magnetic properties, suggesting a limited effect of $\mathrm{Zn}$ addition. It is interesting to note that heat-treatment increases the coercivity when $\mathrm{Zn}$ substitution is low and decreases the coercivity when $\mathrm{Zn}$ content is high.

Figure 5 plots the $\mathrm{M}-\mathrm{T}$ and $\Delta \mathrm{T}$ - $\mathrm{T}$ curves for the samples. The Currie temperature of $\mathrm{Mn}_{54} \mathrm{Al}_{42.7} \mathrm{Zn}_{3.3}, \mathrm{Mn}_{54}$ $\mathrm{Al}_{44.4} \mathrm{Zn}_{1.6}, \mathrm{Mn}_{53.5} \mathrm{Zn}_{0.5} \mathrm{Al}_{46}$ determined by using $\mathrm{dM} / \mathrm{dT}$ method is in the vicinity of $371 \mathrm{~K}-373 \mathrm{~K}$, which is lower than the $388 \mathrm{~K}$ reported for $\tau$-MnAl[3]. The result indicates that $\mathrm{Zn}$ substitution reduces the Currie temperature of $\tau$-MnAl. The endothermal peak observed in Figure 5(d) was ascribed to the ferromagnetic-paramagnetic transition of $\tau$ - MnAl in $\mathrm{Mn}_{54} \mathrm{Al}_{42.7} \mathrm{Zn}_{3.3}$.

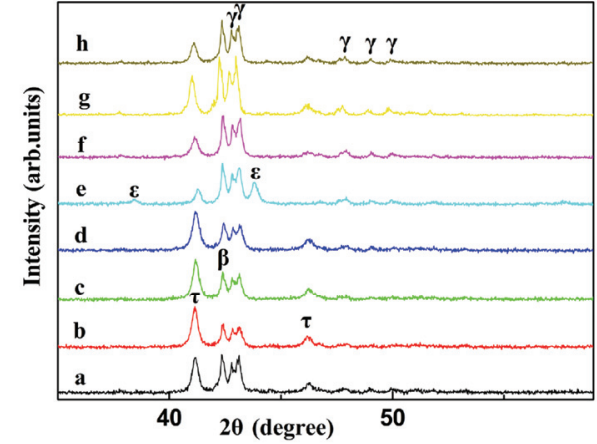

Figure 3. XRD patterns for (a) $\mathrm{Mn}_{53.5} \mathrm{Zn}_{0.5} \mathbf{A l}_{46}$, (b) Heattreated $\mathrm{Mn}_{53.5} \mathrm{Zn}_{0.5} \mathrm{Al}_{46}$, (c) $\mathrm{Mn}_{53.4} \mathrm{Zn}_{1.6} \mathrm{Al}_{46}$, (d) Heat-treated $\mathrm{Mn}_{53.4} \mathbf{Z n}_{1.6} \mathbf{A l}_{46}$, (e) $\mathbf{M n}_{51.8} \mathbf{Z n}_{3.2} \mathbf{A l}_{46}$, (f) Heat-treated $\mathbf{M n}_{51.8}$ $\mathrm{Zn}_{3.2} \mathbf{A l}_{46}$, (g) $\mathrm{Mn}_{49} \mathrm{Zn}_{5} \mathrm{Al}_{46}$, and (h) Heat-treated $\mathrm{Mn}_{49} \mathrm{Zn}_{5} \mathrm{Al}_{46}$. The heat-treatment for sample (b), (d), (f), and (h) was carried out in vacuum under $420^{\circ} \mathrm{C}$ for one hour.

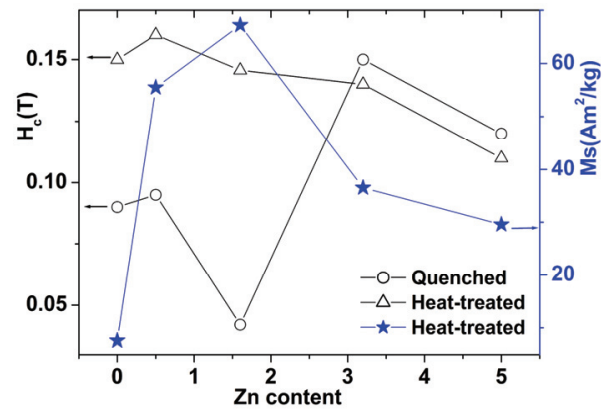

Figure 4. The effect of $\mathrm{Zn}$ substitution to $\mathrm{Mn}$ on the magnetic properties of $\mathbf{M n}_{54} \mathbf{A l}_{46}, M_{\mathbf{5 3}_{5.5}} \mathbf{Z n}_{0.5} \mathbf{A l}_{46}, \mathbf{M n}_{53.4} \mathbf{Z n}_{1.6}$ $\mathrm{Al}_{46}, \mathrm{Mn}_{51.8} \mathrm{Zn}_{3.2} \mathrm{Al}_{46}$ and $\mathrm{Mn}_{49} \mathrm{Zn}_{5} \mathrm{Al}_{46}$.

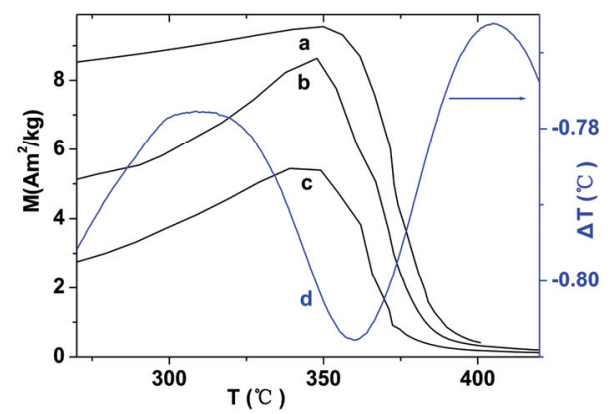

Figure 5. Temperature dependence of magnetization of heat-treated samples (a) $\mathbf{M n}_{54} \mathbf{A l}_{42.7} \mathbf{Z n}_{3.3}$, (b) $\mathbf{M n}_{54} \mathbf{A l}_{44.4} \mathbf{Z n}_{1.6}$, (c) $\mathrm{Mn}_{53.5} \mathrm{Zn}_{0.5} \mathrm{Al}_{46}$ in an applied field of $0.05 \mathrm{~T}$ and a sweep rate of $5^{\circ} \mathrm{C} / \mathrm{min}$. Line (d) plots the $\mathrm{T}-\Delta \mathrm{T}$ data from thermal analysis on $\mathrm{Mn}_{54} \mathrm{Al}_{42.7} \mathbf{Z n}_{3.3}$.

\section{Conclusions}

$\mathrm{Zn}$ substitution can stabilize the structure of $\tau$-phase. $\mathrm{Zn}$ increases the coercivity and saturation magnetization of the $\tau$-MnAl but reduces the Currie temperature. It should be noted that excess $\mathrm{Zn}$ is detrimental to the magnetic 
parameters. The optimum magnetic performance was found in samples with $\mathrm{Zn}$ substitution to $2.9 \% \mathrm{Mn}$ atoms and $3.5 \% \mathrm{Al}$ atoms, respectively.

\section{Acknowledgements}

This work was supported by the Natural Science Foundation of China (Nos. 10874159, 11074227, 50801039), Zhejiang Provincial Natural Science Foundation of China (No. R6110362), and Fundamental R\&D Program for Core Technology of Materials funded by the Ministry of Knowledge Economy, R. Korea.

\section{References}

[1] H. Kono, "On the Ferromagnetic Phase in Manganese-Aluminum System," Journal of the Physical Society of Japan, Vol. 13, No. 12, 1958, pp. 1444-1451.

[2] Q. Zeng, I. Baker, J. B. Cui and Z. C. Yan, "Structural and Magnetic Properties of Nanostructured Mn-Al-C Magnetic Materials," Journal of Magnetism and Magnetic Materials, Vol. 308, No. 2, 2007, pp. 214-226.

[3] J. H. Park, Y. K. Hong, S. Bae, J. J. Lee, J. Jalli, G. S. Abo, N. Neveu, S. G. Kim, C. J. Choi and J. G. Lee, "Saturation Magnetization and Crystalline Anisotropy Calculations for MnAl Permanent Magnet," Journal of
Applied Physics, Vol. 107, No. 9, 2010, pp. 09A731.

[4] Y. Kurtulus and R. Dronskowski, "Electronic Structure, Chemical Bonding, and Spin Polarization in Ferromagnetic MnAl," Journal of Solid State Chemistry, Vol. 176, No. 2, 2003, pp. 390-399. doi:10.1016/S0022-4596(03)00242-1

[5] Y. Sakka, M. Nakamura and K. Koshimoto, "Rapid Quenching and Properties of Hard Magnetic Materials in MnAl-X (X=Ti, Cu, Ni, C, B) Systems," Journal of Materials Science, Vol. 24, No. 12, 1989, PP. 4331-4338

[6] W. H. Dreizler and A. Menth, "Transformation Kinetics of the Ferromagnetic Alloy Mn-Al-C," IEEE Transactions on Magnetics, Vol. 16, No. 3, 1980, PP. 534-536.

[7] D. C. Crew, P. G. McCormick and R. Street, "MnAl and MnAlC Permanent Magnets Produced by Mechanical Alloying," Scripta Metallurgica et Materialia, Vol. 32, No. 3, 1995, PP. 315-318.

[8] M. Mat, A. Mor and N. Koh, "Crystal Structure and Magnetic Properties of Mn-Al-Ni Ferromagnetic Films," IEEE Translation Journal on Magnetics in Japan, Vol. 6, No. 2, 1991, pp. 134-140 doi:10.1109/TJMJ.1991.4565123

[9] R. Kainuma, M. Ise, K. Ishikawa, I. Ohnuma and K. Ishida, "Phase Equilibria and Stability of the B2 Phase in the $\mathrm{Ni}-\mathrm{Mn}-\mathrm{Al}$ and $\mathrm{Co}-\mathrm{Mn}-\mathrm{Al}$ systems," Journal of Alloys and Compounds, Vol. 269, 1998, pp. 173-180. doi:10.1016/S0925-8388(98)00127-3 